\title{
Diurnal Fluctuation in the Concentrations of B Group Vitamins in Water in the Southern Lake Biwa
}

\author{
Akira KurATA*, Takuro KAWASE*, and Hajime KADOTA* \\ (Received August 13, 1981)
}

\begin{abstract}
Diurnal variations in the concentrations of B group vitamins in the water of southern Lake Biwa were studied by observations at intervals of $12 \mathrm{hr}$. It was found that the concentrations of thiamine, biotin and vitamin $B_{12}$ were generally high in the morning and low in the evening during the investigation period. Such diurnal rhythmical fluctuation was repeatedly observed unless there had been a heavy rain. The amounts of particulate matter and chlorophyll $a$ in seston of large and small sizes increased during the daytime and it was usually larger in the morning than in the evening. These data suggest that the diurnal rhythmical changes in the concentrations of $B$ group vitamins in water are due to the balance between autochthonous production of these vitamins mainly by microorganisms and the consumption of them mainly by phytoplankton.
\end{abstract}

Since the requirement of $\mathbf{B}$ group vitamins by 74 species of unicellular algae including marine and fresh water species was reviewed by ProVASOLI, ${ }^{1)}$ the ecological significance of these vitamins in the aquatic environments has been studied by many workers. The distribution of thimaine, biotin and vitamin $B_{12}$ in natural waters has been investigated by CARLUCCI and BOWES ${ }^{2)}$ and OHwada and Taga. ${ }^{3)}$ Recently, Pommel ${ }^{4)}$ reported the inverse relationship of the seasonal changes in the concentration of dissolved inorganic phosphate and vitamin $B_{12}$ to the seasonal change in Oscillatoria rubescens in Lake Leman. Previously, we also reported that there was an inverse relationship between the seasonal variations in the concentrations of B group vitamins and the dynamics of phytoplankton in Lake Mergozzo in northern Italy. ${ }^{3)}$ According to our paper, ${ }^{b)}$ the increase of chlorophyll $a$, phytoplankton populations and also primary productivity was attended with the decrease in the concentration of B group vitamins in water, seasonally. In those works, however, observations were made at the intervals of one month or more. And very few works have been made on the diurnal changes in the concentrations of $\mathrm{B}$ group vitamins in natural waters. As reported by TILZER ${ }^{\text {g) }}$ the activity of primary production by various kinds of phytoplankton is vey changable in a day. Then, it is quite probable that the concentrations of B group vitamins, essential for many kinds of primary producers, must also be

\section{fluctuated in a day.}

In the present paper, we tried to make clear the diurnal fluctuations in the concentrations of $\mathbf{B}$ group vitamins during a week in water in the southern Lake Biwa. The relationship between fluctuations of B group vitamins and those of phytoplankton were discussed.

\section{Materials and Methods}

Water samples for the assay of $B$ group vitamins were collected from $0.5 \mathrm{~m}$ layer in the southern Lake Biwa by a Van Dorn water sampler every $12 \mathrm{hr}$ from June 3 to 10 of 1976 . The location of the sampling stations is shown in Fig. 1. Sampling was made immediately after the sunrise and at the time just before the sunset every day during the investigation period, in order to know the influences to the concentrations of $B$ group vitamins caused by the photosynthetic activity of phytoplankton communities. The concentrations of B group vitamins and chlorophyll $a$ were determined by the method as described in the previous paper. ${ }^{b)}$ Particulate matter was determined by filtering water sample through glass fiber filter (1.2 $\mu$ porosity).

\section{Results and Discussion}

The first half of the investigation period, from June 3 to 7 , the weather was fine and it was a little cloudy on June 8 , thereafter it was rain.

* Department of Fisheries, Faculty of Agriculture, Kyoto University, Kyoto 606, Japan (倉田 亮 - 河瀬

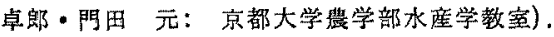




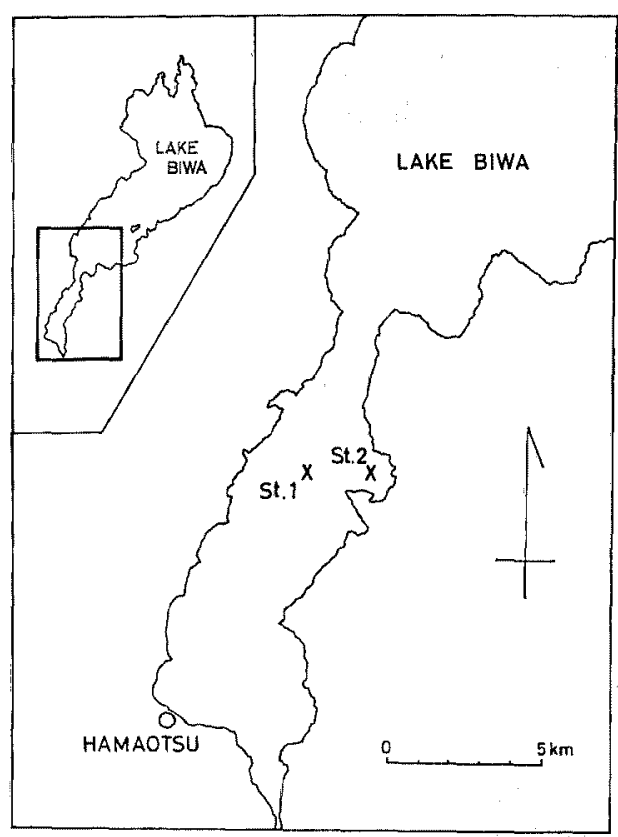

Fig. 1. Location of the sampling stations in the southern Lake Biwa.

Diurnal variations of the amount of particulate matter and chlorophyll $a$ at Station 1 during the investigation period are shown in Fig. 2. The amount of particulate matter of which the most part is composed of phytoplankton populations always decreased from the evening to the early morning during the first three days of the investigation period. With the exception of June 10 , the amount of particulate matter at this station increased during the daytime. The diurnal fluctuation in the amount of particulate matter showed a similar trend to that of chlorophyll $a$ in seston of large and small sizes. This appears to be a positive proof of the variation of phytoplankton populations. The increase during the daytime and the decrease during the night in the concentration of chlorophyll $a$ in the surface water suggested the vigorous growth of phytoplankton during the daytime or the sedimentation of phytoplankton during the night in the water column. The diurnal fluctuation in the concentration of thiamine at Station 1 in a week period is shown in Fig. 3. The concentration of thiamine generally increased during the night and markedly decreased during the daytime. The increase during the night and the decrease in the daytime in the concentration of thiamine were repeatedly observed during the investigation period. Such diurnal rhythmic changes in the concentrations of $\mathbf{B}$ group vitamins have never been reported till now in the aquatic environments. The concentration of thiamine at Station 1 increased generally throughout the night during the investigation period with a few exceptions. As reported by previous paper, ${ }^{7)}$ the vitamins were produced consistently throughout the day by different kinds of microorganisms in water, excluding the transudation of the vitamins from the bottom sediments. ${ }^{\text {b) }}$ From these facts, it is suggested that the consumption of thiamine by phytoplankton attended with the photosynthetic activity surpass the allochthonous supply or the production of the vitamin by various kinds of microorganisms in the water.

The diurnal fluctuation in the concentration of biotin at Station 1 during a week is shown in Fig. 4. In the case of biotin, not so distinct rhythmic fluctuation was found in the diurnal

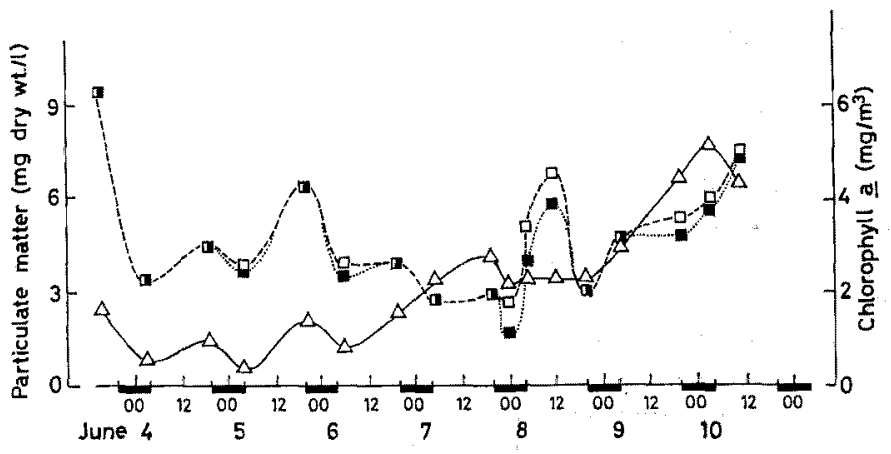

Fig. 2. Diurnal variations of particulate matter and chlorophyll $a$ in water during the investigation period at Station 1 in the southern Lake Biwa.

$\triangle$, particulate matter $(>1.2 \mu) ; \square$, chlorophyll $a$ in seston of large size $(>70 \mu)$; chlorophyll $a$ in seston of small size $(<70 \mu,>25 \mu)$. 


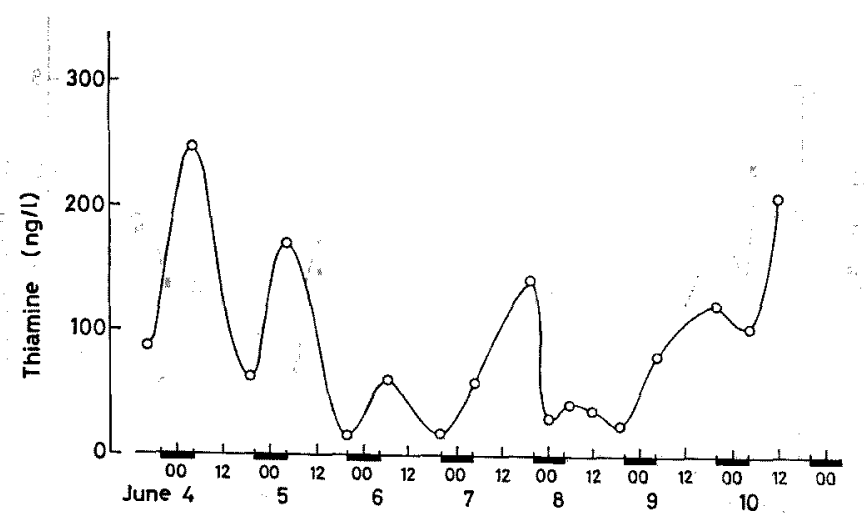

Fig. 3. Diurnal variations in the concentrations of thiamine during the investigation period at Station 1.

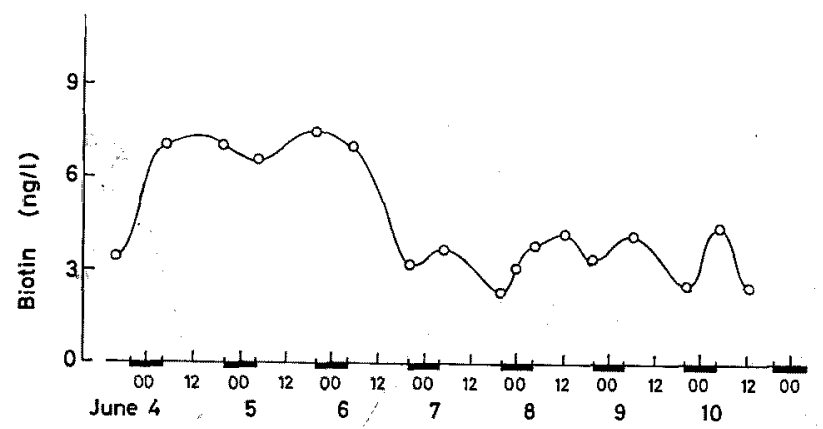

Fig. 4. Diurnal variations in the concentrations of biotin during the investigation period at Station 1.

changes of the concentration, and the concentration was rather higher in the first half of the investigation period than in the latter half. Such fluctuatica pattern in the concentration of biotin differed considerably from the diurnal fluctuation in the concentration of thiamine. This may be due to the difference in the requirement for both the vitamins by phytoplankton community during the first half period at this station.

The diurnal fluctuation in the concentration of vitamin $\mathbf{B}_{12}$ and the amount of chlorophyll $a$ during the investigation period at Station 1 are shown in Fig. 5. The diurnal fluctuation pattern in the concentration of vitamin $B_{12}$ in water from the evening of June 3 to the early morning of June 9 showed a similar trend to that of thiamine. The concentration of vitamin $\mathrm{B}_{12}$ increased throughout the night and decreased throughout the daytime. Such diurnal fluctuation was repeatedly observed. The diurnal rhythmical changes in the concentration of vitamin $B_{12}$ like that have not been reported in natural waters.
It is thought that the diurnal rhythmical changes in the concentration of the vitamin as mentioned above were caused as a result of the autochthonous production by the various kinds of microorganisms and the consumption by phytoplankton requiring the vitamin. The amount of the vitamin consumed by phytoplankton during the daytime may be much more than that during the night at which photosynthesis does not take place. As shown in Fig. 5, therefore, an inverse trend was observed between the concentration changes of vitamin $\mathbf{B}_{12}$ and chlorophyll $a$ during the investigation period.

Secondarily, the diurnal variation in the amount of particulate matter during the investigation period at Station 2 is shown in Fig. 6. The increase during the night and the decrease during the daytime in the amount of particulate matter which was approximately three times as large as at Station 1 was periodically repeated three times at the intervals of $12 \mathrm{hr}$ from the evening of June 3 to the early morning of June 6. An extremely high value in the amount of particulate matter 


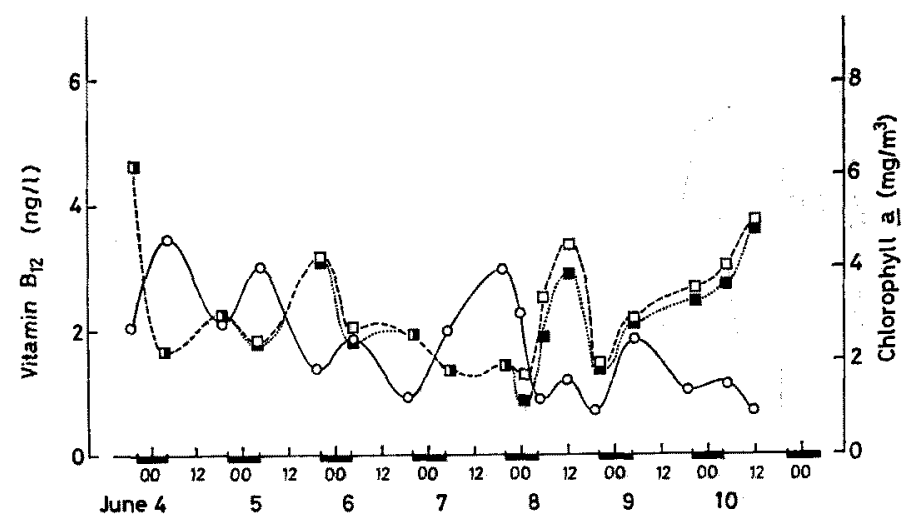

Fig. 5. Diurnal variations in the concentrations of vitamin $B_{12}$ and chlorophyll $a$ during the investigation period at Station 1.

$\mathrm{O}$, vitamin $\mathrm{B}_{\mathbf{1 2}} ; \square$, chlorophyll $a$ in seston of large size $(>70 \mu) ; \boldsymbol{m}$, chlorophyll $a$ in seston of small size $(<70 \mu,>25 \mu)$.

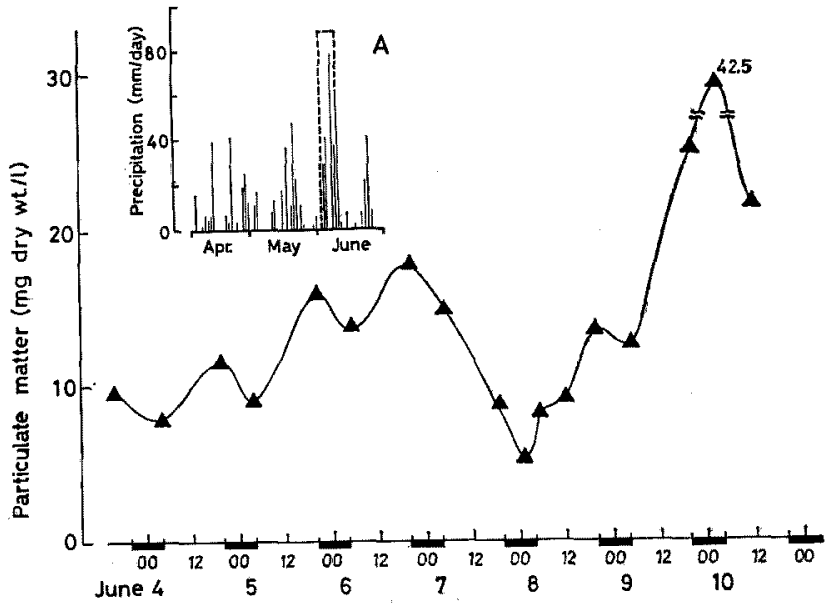

Fig. 6. Diurnal variations of particulate matter in water during the investigation period at Station 2. $\Delta$, particulate matter $(>1.2 \mu) ; \mathrm{A}$, precipitation in the spring of 1976 . The enclosed area with a dotted line represents the investigation period.

obtained at the early morning of June 10 may be consequences of heavy drainage containing a large quantity of abioseston derived from the river near this station as shown in Fig. 6A.

Diurnal fluctuations in the concentrations of thiamine, biotin and vitamin $B_{12}$ in water at Station 2 are shown in Figs. 7, 8 and 9. The concentration ranges of thiamine, biotin and vitamin $\mathrm{B}_{12}$. were from 80.0 to $580.1 \mathrm{ng} / l$, from 3.1 to $28.5 \mathrm{ng} / l$ and from 0.85 to $8.12 \mathrm{ng} / l$, respectively, and these values were larger than those at Station 1. Likewise in the case of vitamin $\mathbf{B}_{12}$ at Station 1 , an inverse relationship was found between the concentration changes of vitamin $\mathbf{B}_{12}$ and chlo- rophyll $a$ at Station 2 during the investigation period.

Recently, MAULOOD et al. ${ }^{0 /}$ studied the diurnal variations of major chemical, physical and biological variables in Loch Lomond, England and reported that in the phytoplankton community Tabellaria fenestrata was dominant and it showed the maximum abundance in the early morning. The concentration of chlorophyll $a$ also showed periodical pattern with a single peak between 10:00 and 14:00 everyday. It was also reported that some chemical variables showed an inverse correlation to the periodical pattern of cell multiplication. However, the diurnal variations in 


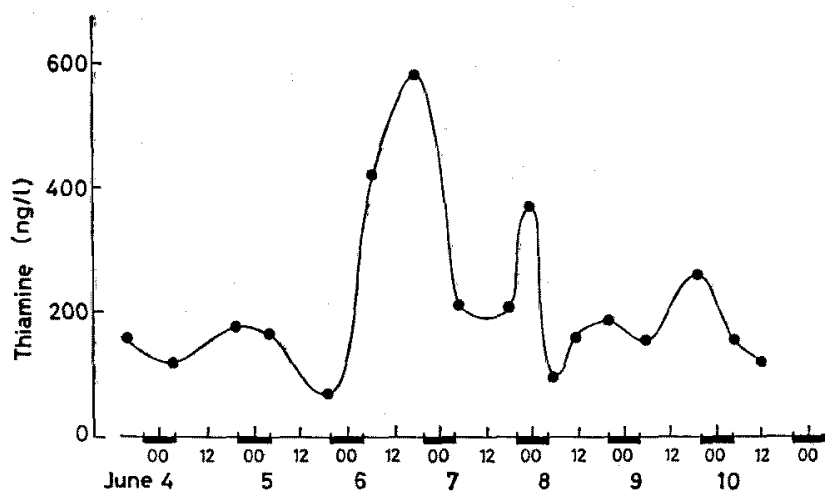

Fig. 7. Diurnal variations in the concentrations of thiamine during the investigation period at Station 2.

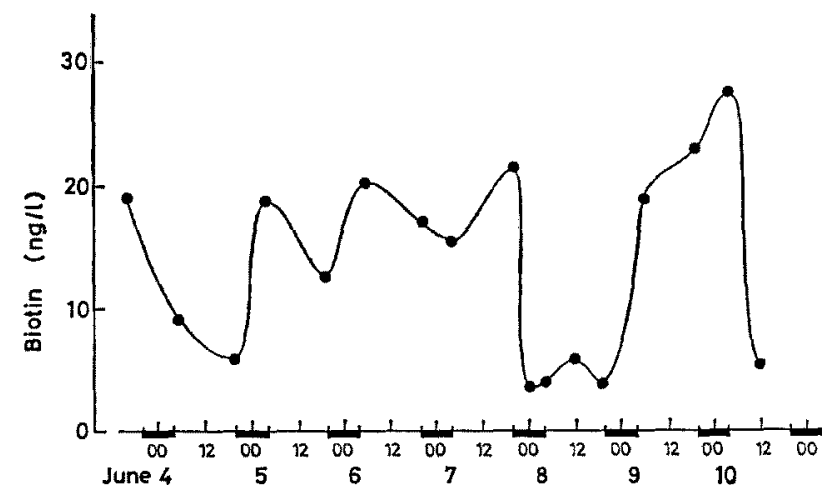

Fig. 8. Diurnal variations in the concentrations of biotin during the investigation period at Station 2.

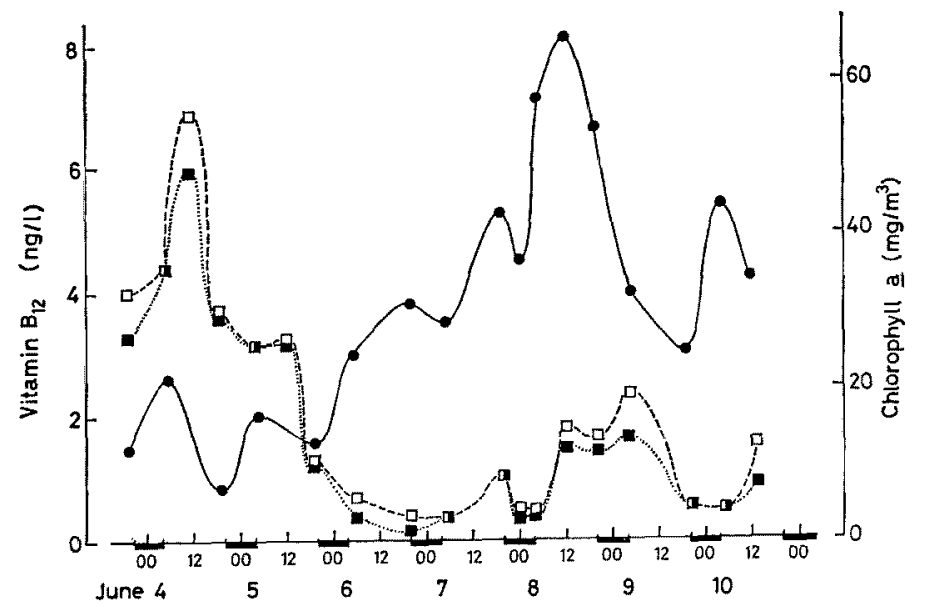

Fig. 9. Diurnal variations in the concentrations of vitamin $\mathrm{B}_{12}$ and chlorophyll $a$ during the investigation period at Station 2.

, vitamin $\mathrm{B}_{12} ; \square$, chlorophyll $a$ in seston of large size $(>70 \mu)$; $\mathbf{w}$, chlorophyll $a$ in seston of small size $(<70 \mu,>25 \mu)$. 
the concentrations of $\mathbf{B}$ group vitamins have never been reported. The trend of periodical changes in the concentrations of B group vitamins found in this study suggests that there might be an inverse relationship between the diurnal changes of B group vitamins and those of chlorophyll $a$ reported by MAULood et al. This idea may also be supported by our previous study on the dynamics of B group vitamins, primary productivity and phytoplankton in Lake Mergozzo:"

\section{Acknowledgements}

We are very grateful to Dr. M. NAKanishi and others of Otsu Hydrobiological Station of Kyoto University for giving us the data of chlorophyll $a$ and providing us the technical assistance during the investigation period.

\section{References}

1) L. Provasoli: Ann. Rev. Microbiol., 12, 279308 (1958).

2) A. F. CarlucCi and P.M. Bowes: Limnol. Oceanogr., 17, 774-776 (1972).

3) K. OHWADA and N. TAGA: Limnol. Oceanogr., 17, 315-320 (1972).

4) B. Pommel: Ann. Hydrobiol, 6, 103-121 (1975).

5) A. Kurata, C. Saraceni, D. Ruggiu, M. NakaNISHI, U. MELChIORRI-SANTOLINI, and H. KaDOTA: Mem. Ist. Ital. Idrobiol., 33, 257-284 (1976).

6) M. M. TIlzer: Limnol. Oceanogr., 18, 15-30 (1973).

7) A. Kurata, C. Saraceni, and H. Kadota: Mem. Ist. Ital. Idrobiol., 37, 87-103 (1979).

8) A. KúRATA: J. Oceanogr. Soc. Japan. 26, 81-86 (1970).

9) B. K. Maulood, G. C. F. Hinton, and A. D. BONEY: Hydrobiologia, 58, 99-117 (1978). 